\title{
A descriptive study of gender preference and its relation to willingness for sterilization in pregnant women in a tertiary hospital in Goa
}

\author{
Deepa B. Karmali ${ }^{1 *}$, Guruprasad Pednekar ${ }^{1}$, Radha Valaulikar ${ }^{2}$, Umesh S. Kamat $^{3}$
}

\author{
${ }^{1}$ Department of Obstetrics \& Gynaecology, Goa Medical College, Goa, India \\ ${ }^{2}$ Department of Preventive and Social Medicine, JJM Medical College, Davangere, India \\ ${ }^{3}$ Department of Preventive Medicine, Goa Medical College, Goa, India
}

Received: 15 February 2016

Accepted: 23 February 2016

\section{*Correspondence:}

Dr. Deepa B. Karmali,

E-mail: karmalideepa@gmail.com

Copyright: () the author(s), publisher and licensee Medip Academy. This is an open-access article distributed under the terms of the Creative Commons Attribution Non-Commercial License, which permits unrestricted non-commercial use, distribution, and reproduction in any medium, provided the original work is properly cited.

\begin{abstract}
Background: There is an association between male gender preference and avoidance of ligation if preferred sex is not born. We therefore undertook this study to systematically analyze this association between the gender preference and willingness for sterilization in Goan women.

Methods: A hospital based cross sectional descriptive study was undertaken among 216 women attending antenatal clinic at a tertiary hospital in Goa between August to December 2015. The data was analyzed in SPSS for Windows, version 14.0. The results are described as percentages and assessment of statistically significant difference was done using the Chi-Square test at $95 \%$ level of significance $(\mathrm{p}<0.05)$.

Results: Of the 216 women who participated in the study, 50 (23.1\%) had a male preference. Age, education of the women and religion were not found to be having a statistically significant association with the male preference. Occupation, socio-economic status of the women and parity were found to be having a statistically significant association with the male preference. The women with one surviving male child did not mind if the second child was female but those with previous female child desired for male child in most instances. Eighty three percent of women with preference for female child were willing for ligation even if their preference was not met compared to only $50 \%$ of those with male preference.

Conclusions: The decision on completion of family as evident from willingness for sterilization is influenced by the sex preference and the outcome of pregnancy in terms of the sex of the child.
\end{abstract}

Keywords: Gender preference, Male preference, Ligation

\section{INTRODUCTION}

Female sterilization, a permanent method of contraception, should be offered to every woman with two living issues. However, it is common in day to day clinical practice to find that the couples postpone sterilization till the male child is born. This 'want for male child', is further evident by the declining sex ratio in India which was 940 females per 1000 males in $2011{ }^{1}$ The sex ratio in Goa is 973 females per 1000 males despite high female literacy and higher per capita income. ${ }^{1}$ We therefore undertook this study to systematically analyze this association between the gender preference and willingness for sterilization in Goan women.

The objectives of the study was to estimate the proportion of pregnant women attending antenatal clinic in a tertiary hospital in Goa, who have a preference for male child and to study the association between preference for male child and a woman's willingness for sterilization. 


\section{METHODS}

A hospital based cross sectional descriptive study was undertaken among 216 women attending antenatal clinic at a tertiary hospital in Goa between August to December 2015. A sample size of 216 was calculated assuming that $50 \%$ of women will indicate a gender preference (proportion to yield maximum sample size). An absolute precision of $7 \%$ and $95 \%$ confidence intervals were considered. A non-response rate of $10 \%$ was considered, to the calculated sample size of 196 , giving a final sample size of 216. Women with no living issue were excluded as they are anyway not eligible for sterilisation. The study protocol was approved by the Ethics Review Committee of Goa Medical College Hospitals, Bambolim, Goa. The data was analysed in SPSS for Windows, version 14.0. The results are described as percentages and assessment of statistically significant difference was done using the Chi-Square $\left(\chi^{2}\right)$ test at $95 \%$ level of significance $(\mathrm{p}<0.05)$.

\section{RESULTS}

Table 1: Association of male preference with sociodemographic variables.

\begin{tabular}{|c|c|c|c|c|}
\hline Variables & $\mathbf{N}$ & Male preference (\%) & $x^{2}$ & $\mathbf{P} *$ \\
\hline \multicolumn{5}{|l|}{ Age Group } \\
\hline$\leq 20$ & 10 & 0 & 7.929 & 0.16 \\
\hline $21-25$ & 55 & $11(20 \%)$ & & \\
\hline $26-30$ & 91 & $21(23.1 \%)$ & & \\
\hline $31-35$ & 44 & $13(29.5 \%)$ & & \\
\hline $36-40$ & 15 & $4(26.7 \%)$ & & \\
\hline$>40$ & 1 & $1(100 \%)$ & & \\
\hline Total & 216 & $50(23.1 \%)$ & & \\
\hline \multicolumn{5}{|l|}{ Education } \\
\hline Less than SSC & 122 & $32(26.2 \%)$ & 4.482 & 0.345 \\
\hline SSCE to HSSCE & 76 & $13(17.1 \%)$ & & \\
\hline Graduate & 16 & $5(31.2 \%)$ & & \\
\hline Post-graduate & 2 & 0 & & \\
\hline Total & 216 & $50(23.1 \%)$ & & \\
\hline \multicolumn{5}{|l|}{ Religion } \\
\hline Catholic & 6 & 0 & 2.819 & 0.42 \\
\hline Hindu & 165 & $41(24.9 \%)$ & & \\
\hline Muslim & 45 & $9(20 \%)$ & & \\
\hline Total & 216 & $50(23.1 \%)$ & & \\
\hline \multicolumn{5}{|l|}{ Occupation } \\
\hline No & 189 & $47(24.9 \%)$ & 4.106 & 0.043 \\
\hline Yes & 27 & $3(11.1 \%)$ & & \\
\hline Total & 216 & $50(23.1 \%)$ & & \\
\hline \multicolumn{5}{|l|}{ Socio economic status } \\
\hline 2 & 110 & $18(16.4 \%)$ & 7.914 & 0.048 \\
\hline 3 & 71 & $22(31 \%)$ & & \\
\hline 4 & 29 & $7(24.1 \%)$ & & \\
\hline 5 & 6 & $3(50 \%)$ & & \\
\hline Total & 216 & $50(23.1 \%)$ & & \\
\hline \multicolumn{5}{|l|}{ Parity } \\
\hline 1 & 149 & $26(17.5 \%)$ & 10.769 & 0.005 \\
\hline 2 & 50 & $19(38 \%)$ & & \\
\hline 3 & 17 & $5(29.4 \%)$ & & \\
\hline Total & 216 & $50(23.1 \%)$ & & \\
\hline \multicolumn{5}{|c|}{ Number of live male Issues } \\
\hline No male child & 111 & $43(38.7 \%)$ & 33.552 & $\mathbf{0}$ \\
\hline More than/Equal to 1 & 105 & $7(6.7 \%)$ & & \\
\hline
\end{tabular}


Table 2: Willingness for ligation if preferred sex is not born, according to the male preference.

\begin{tabular}{|llll|}
$\begin{array}{|lll|}\text { Preference for male } \\
\text { sex }\end{array}$ & \multicolumn{2}{l|}{ Willingness for ligation } & Total \\
\hline & Yes & No & 50 \\
\hline Yes & $25(50 \%)$ & $25(50 \%)$ & 166 \\
\hline No & $132(80 \%)$ & $34(20 \%)$ & 216 \\
\hline
\end{tabular}

$\chi 2=17.531 ; \mathrm{df}=1 ; \mathrm{p}=0.000$

Table 3: Willingness for ligation if preferred sex is not born, according to the female preference.

\begin{tabular}{|lllc|}
$\begin{array}{l}\text { Preference for } \\
\text { female sex }\end{array}$ & \multicolumn{2}{c}{ Willingness for ligation } & Total \\
\hline & $25(83.3 \%)$ & $5(16.6 \%)$ & 30 \\
\hline Yes & $132(71 \%)$ & $54(29 \%)$ & 186 \\
\hline No & $157(72.7 \%)$ & $59(27.3 \%)$ & 216 \\
\hline
\end{tabular}

$\chi 2=3.092 ; \mathrm{df}=1 ; \mathrm{p}=0.213$

Of the 216 women who participated in the study 50 (23.1\%) had male preference, $30(13.8 \%)$ had female preference while the rest revealed no specific preference. The patients were evaluated with regards to their sociodemographic profile. Factors studied were age, education, religion, occupation, socio-economic status and parity, and their relation to the male preference was studied. Age, education of the women and religion were not found to have a statistically significant association with the male preference (Table 1). Occupation, socio-economic status of the women and parity were found to have a statistically significant association with the male preference (Table 2).

The women who had no living male issue had a male preference of $38.7 \%$ while the women with more than or equal to one male living issues had a male preference of $5.7 \%(\mathrm{p}=0.000)$. The women who had no living female issue had a male preference of $2.4 \%$ whereas the women with more than or equal to one female living issue had male preference of $35.6 \%(\mathrm{p}=0.000)$. As evident from Table 3 and 4 , it is seen that $50 \%$ of women who had a preference for male child were willing for ligation if the child with preferred sex was not born compared to $80 \%$ of those with no such preference were willing for ligation. This difference was found to be statistically significant $(\mathrm{p}<0.05)$. On the other hand the difference between the proportion of women with and without preference for female child did not differ significantly in terms of willingness for ligation even if the child of preferred sex was not born $(\mathrm{p}=0.213)$.

\section{DISCUSSION}

Inclination towards a child of specific sex during pregnancy is not a rarity. ${ }^{2}$ The reasons for male preference are carrying forward of family name, old age support and performance of last rites whereas female preference is for emotional support, to do the household work and to take care of siblings. Females are also not preferred due to the dowry system. We studied the type of gender preference in the antenatal patients coming to our institution.

In our study, $62.9 \%$ of the women did not have a gender preference while $23.1 \%$ had a male sex preference and $13.8 \%$ had a female sex preference. Kumar $\mathrm{N}$ et al also showed that majority of the patients $(60.6 \%)$ in his study did not have gender preference. ${ }^{2}$ Studies across India have revealed varying degrees of male preference from $27 \%$ to $41 \% .^{3-5}$ It is understood that preference for male child is a function of various sociodemographic variables like education, social class, occupation, urban rural differences, with more developed societies being neutral towards sex preference. Given the high female literacy rate in Goa, late age at marriage, late age at first pregnancy and being primarily an urban state the figure of $63 \%$ being neutral in terms of their sex preference during the pregnancy is not beyond expectation. ${ }^{1}$ A study by Kumar BSS et al showed that $73 \%$ of the mothers did not have any preference and $27 \%$ of the mothers had a male sex preference, which is similar to that seen in our study. ${ }^{4}$ Other studies by Bhattacharjya et al and Paul et al found that the preference for male sex, female sex and no preference was $40.8 \%, 29.7 \%$ \& $29.5 \% ; 40.3 \%, 19.4 \%$ \& $40.3 \%$, respectively. ${ }^{5,6}$ None of the studies showed a higher preference for females compared to males.

Preference for male child was found to increase across the advancing age groups; with those more than 35 years of age being 1.84 times more likely to have a male preference compared to those less than 35 years of age; but the difference was not statistically significant. Kumar $\mathrm{N}$ et $\mathrm{al}^{2}{ }^{2}$ however, found that women above 30 years preferred a female child. A study by International Centre for Research on Women (ICRW) reported mothers' education as the single most significant factor in reducing son preference; however, we did not find any linear trend across the education groups in our study population. ${ }^{7}$ Kumar BSS et al also found that higher education reduces the preference for male child in conformity with findings by ICRW. ${ }^{4}$ Being the only tertiary government hospital catering to the health needs of people in Goa and border areas of Karnataka and Maharashtra the effect of education might have been overshadowed by the sociocultural influence of these border states of Goa. The male preference among Hindus and Muslims was $24.9 \%$ and $20 \%$, respectively, which is in contrast to the study by Paul et al which showed it to be $50 \%$ and $31.7 \%$, respectively. ${ }^{6}$ It is remarkable that Catholics did not seem to have any preference for male child in contrast to Hindus and Muslims, thereby emphasising the role of cultural influences in gender preference. The employed women were less likely to have preference for male child compared to those not employed thereby reinforcing the role of women empowerment in gender equality. No such association between employment status and male preference was demonstrated by Bhattacharjya et al as well as by Kumar $\mathrm{N}$ et al. ${ }^{2,5}$ It is believed that overall 
socioeconomic development is an answer to gender disparity. However based on our findings we hypothesise that the gender bias is too deeply rooted in our sociocultural and also emotional milieu that mere improvement in socioeconomic status is insufficient to address the issue. This hypothesis is reinforced with our finding that the preference for male child is higher among those belonging to socioeconomic strata $3 \& 4(28 \%)$ compared to those in $1 \& 2(20 \%)$. Similar comment on gender preference and socioeconomic development is made by Kumar $\mathrm{N}$ et al. $^{2}$

Our study showed statistically significant association between the presence and absence of living female children with the male gender preference which was comparable to that showed by Paul et al. ${ }^{6}$ There was also a statistically significant association between the presence and absence of living male children with regards to the male preference which was also seen in the study by Bhattacharjya et al. ${ }^{5}$ The women with no living male child were almost 10 times more likely to have male preference compared to those with no surviving female child. All the women in our study group had at least one surviving child. Thus, the women with one surviving male child did not mind if the second child was female but those with previous female child desired for male child in most instances. This attitude appears to be promale rather than anti-female gender. The fact that $83.3 \%$ of women with preference for female child were willing for ligation even if their preference was not met compared to only $50 \%$ of those with male preference speaks of the reproductive goals of the couple- the saying that 'every woman should become pregnant and every man should have a son' appears to be true. ${ }^{8}$ This compares with the study by Bangal et al where only $4 \%$ accepted ligation in the absence of a male child while $25 \%$ accepted ligation in the absence of a female child. ${ }^{9}$

\section{CONCLUSION}

In this hospital based study at a tertiary hospital in Goa, $23.1 \%$ of the women with at least one living issue seemed to have preference for male gender. The preference for male gender seemed to be influenced by the gender of the surviving issues rather than the variables like age, religion, and education. Further, the decision on completion of family as evident from willingness for sterilisation is influenced by the sex preference and the outcome of pregnancy in terms of the sex of the child. The effects of cultural influences on gender bias seem to be too strong to be washed away with interventions like education and economic development. It may take a few more generations to see the desired gender equality which appears to be an evolution rather than revolution.
Funding: No funding sources

Conflict of interest: None declared

Ethical approval: The study was approved by the Institutional Ethics Committee

\section{REFERENCES}

1. Census of India 2011, Government of India.

2. Kumar N, Tanuj K, Unnikrishnan B, Rekha T, Mithra P, Kulkarni V. Gender preferences among antenatal women: a cross-sectional study from coastal South India. Afr. Health Sci. 2015;15(2):5607.

3. Vedpathak V, Kakrani V, Nagaonkar A, Deo D, Dahire P, Kawalkar U. Gender preference and awareness regarding sex determination among pregnant women- A hospital based study. Int J Med Sci Public Health. 2013;2(4):1054-7.

4. Kumar BSS, Sreegiri S, Naidu SA. A Study on Gender Preference and Awareness on PreConception and Pre-Natal Diagnostic Techniques (PCPNDT) Act Among Antenatal Women in Visakhapatnam City. IOSR Journal of Dental and Medical Sciences. 2015;14(5):106-9.

5. Bhattacharjya H, Das S, Mog C. Gender preference and factors affecting gender preference of mothers attending Antenatal Clinic of Agartala Government Medical College. Int J Med Sci Public Health. 2014;3:137-9.

6. Paul A, Dasgupta S, Bhattacharya S. Gender Preference among the Mothers attending Antenatal Clinic of Burdwan Medical College, West Bengal. Indian Journal of Maternal and Child Health. 2012;16(1):1-8.

7. Pande R, Malhotra A. Son preference and daughter neglect in India. 2006 International Centre for Research on Women (ICRW) $30^{\text {th }}$ Anniversary Bulletin.

8. Park K. Demography and Family Planning. In: Park's Textbook of Preventive \& Social Medicine. $18^{\text {th }}$ ed. Jabalpur: Banarsidas Bhanot Publishers. 2005:349.

9. Bangal V, Giri P. Sex combination of living children at the time of sterilization among rural women of central India. International Journal of Basic and Applied Medical Sciences. 2012;2(3):63-7.

Cite this article as: Karmali DB, Pednekar G, Valaulikar R, Kamat US. A descriptive study of gender preference and its relation to willingness for sterilization in pregnant women in a tertiary hospital in Goa. Int J Reprod Contracept Obstet Gynecol 2016;5:886-9. 